\title{
Macroscopic Urinalysis
}

\subsection{Color}

Depending on concentration, urine is light yellow to dark yellow in color. A noticeable deviation in color from the norm can indicate pathology or be harmless in nature.

\subsubsection{Some Examples}

- Colorless to light yellow

Cause: polyuria, glycosuria in diabetes mellitus

- Dark yellow to orange

Cause: oliguria, anuria, vitamin preparations

- Dark yellow to brownish-yellow

Cause: hemoglobin and hemoglobin degradation products (bilirubin, porphyrins), drugs

- Milky/cloudy

Cause: leukocyturia, salts, crystals

- Red to reddish-brown

Cause: erythrocytes, myoglobin, urates, drugs, beetroot

- Dark brown to black

Cause: erythrocytes, massive hemolysis

\subsection{Odor}

Certain foods, drugs, and bacteria alter the typical odor of urine.

\subsubsection{Some Examples}

- Extremely intensive odor Cause: garlic, asparagus

- Smells like chocolate, highly aromatic

Cause: vitamin preparations, tropical fruits, spices
- Smells of ammonia

Cause: urea-splitting bacteria

- Smells foul, putrid

Cause: urinary tract infection

- Smells of fruit, acetone

Cause: ketonuria

\subsection{Cloudiness}

Fresh urine at body temperature is normally clear. The colder and more concentrated a urine sample becomes, the more salts and crystals precipitate and cause turbidity or cloudiness. Urine also becomes visibly cloudy in the case of a pathological accumulation of bacteria or pyuria.

Only by analyzing solid components in urine (as in urinary sediment analysis) is it possible to conclusively identify the cause of cloudiness.

\subsubsection{Some Examples}

- Milky white

Cause: bacteriuria, pyuria, phosphaturia, vaginal secretion

- Reddish (brick dust) upon cooling

Cause: uraturia

- Red to reddish-brown

Cause: macrohematuria

- Fat layer on the surface

Cause: lipiduria in nephrotic syndrome, ointments, suppositories 